\title{
Arsenolipids are not uniformly distributed within two brown macroalgal species Saccharina latissima and Alaria esculenta
}

\author{
Ásta H. Pétursdóttir ${ }^{1}$. Jonathan Blagden ${ }^{1,2} \cdot$ Karl Gunnarsson $^{3} \cdot$ Andrea Raab $^{2}$ - Dagmar B. Stengel ${ }^{4}$. \\ Jörg Feldmann ${ }^{2} \cdot$ Helga Gunnlaugsdóttir ${ }^{1}$
}

Received: 22 November 2018 / Revised: 24 April 2019 / Accepted: 8 May 2019 / Published online: 31 May 2019

(C) The Author(s) 2019

\begin{abstract}
Brown macroalgae Saccharina latissima (30-40 individuals) and Alaria esculenta (15-20 individuals) were collected from natural populations in winter in Iceland. The algal thalli were sectioned into different parts (e.g. holdfast, stipe, old frond, young frond and sori-containing frond sections) that differed in age and biological function. The work elucidated that arsenic (As) was not uniformly distributed within the two brown macroalgal species, with lower levels of total As were found in the stipe/midrib compared to other thallus parts. The arsenosugars mirrored the total arsenic in the seaweed mainly due to $\mathrm{AsSugSO}_{3}$ being the most abundant As species. However, arsenic speciation using parallel HPLC-ICP-MS/ESI-MS elucidated that the arseniccontaining lipids (AsL) had a different distribution where the arsenosugarphospholipids (AsPL) differed by approximately a factor of 4 between the sections containing the lowest and highest concentrations of AsPLs. When placing the sections in order of metabolic activity and an estimate of tissue age, there appeared to be a relationship between the activity and AsPLs, with lower levels of AsPLs in oldest parts. This is the first time such a relationship has been shown for AsLs. Hence, by applying sophisticated analytical techniques, it was possible to gain a deeper understanding of arsenolipids in seaweed.
\end{abstract}

Keywords Mass spectrometry/ICP-MS · Accurate mass · Identification · Quantification · Seaweed $\cdot$ Arsenic speciation

$\overline{\text { Published in the topical collection Young Investigators in (Bio-)Analytical }}$ Chemistry with guest editors Erin Baker, Kerstin Leopold, Francesco Ricci, and Wei Wang.

Electronic supplementary material The online version of this article (https://doi.org/10.1007/s00216-019-01907-x) contains supplementary material, which is available to authorized users.

Ásta H. Pétursdóttir

astap@matis.is

$\triangle$ Jörg Feldmann

j.feldmann@abdn.ac.uk

1 Matís, Research and Innovation, Vínlandsleið 12, 113 Reykjavík, Iceland

2 Trace Element Speciation Laboratory Aberdeen, University of Aberdeen, Meston Walk, Aberdeen AB24 3UE, UK

3 Marine \& Freshwater Research Institute, Skúlagata 4, 101 Reykjavík, Iceland

4 Botany and Plant Science, School of Natural Sciences, and, Ryan Institute for Environmental, Marine and Energy Research, National University of Ireland Galway, Galway, Ireland

\section{Introduction}

Arsenic is a ubiquitous element in the environment and is found as over 100 naturally occurring arsenic species $[1,2]$. These species exist as both organic and inorganic forms of arsenic and their toxicity is species dependent [3]. There has been significant interest in the inorganic arsenic (iAs, arsenite and arsenate) since it is a known carcinogen [4]. With more information and better analytical techniques to determine iAs, the current legislative focus is shifting from total arsenic (totAs) to iAs [5] due to very different toxicological properties of arsenic species. Organic arsenic has generally been considered less toxic and not a major concern with regard to human health. However, in recent years, light has been shed on the high toxicity of arsenolipids (AsLs) [6]. AsLs can be grouped based on their structure. The main groups of AsLs are arsenohydrocarbons (AsHCs), arseno-fatty acids (AsFAs) and mono- and di-acyl arsenosugarphospholipids (AsPLs also referred to as AsSugPLs) [7-9]. The phospholipids containing As are more diverse than only the AsPLs (i.e. AsSugPLs) and include arsenic-containing phosphatidylcholines (AsPCs) and arsenic-containing phosphatidylethanolamines (AsPEs) [10, 
11]. The arseno-fatty alcohols (TMAsFOHs) are the only AsL group comprising a trimethyl arsenio moiety instead of a dimethyl arsenio moiety [12]. Yu et al. [10] suggest that due to the diversity, i.e. that phosphatidyl lipids can contain both arsenic bound to fatty acids and sugars, these AsLs are formed after the biosynthesis of the arsenic-containing moiety. However, how these species are formed is still unclear.

The AsLs appear to be an emerging threat in food safety, particularly the AsHCs. The AsHCs have shown similar cytotoxicity to iAs [13] although the mode of action of iAs and AsHCs may be different $[13,14]$. AsLs pass the in vitro intestinal barrier model (Caco-2) as well as the blood-brain barrier (BBB) of fruit flies (in vivo) and porcine (in vitro) $[6$, $15,16]$. AsHC360 possesses very high toxic potential where it is five times more cytotoxic than iAs. AsHC332 and AsHC360 disrupt the in vitro BBB and are effective permeability enhancers and might therefore facilitate the transfer of other foodborne toxicants into the brain [6]. AsLs have also been found in human breast milk [17]. Seaweed can contain high amounts of AsHCs, where the toxic AsHC360 has been shown to be the dominant AsL in brown filamentous algae such as Ectocarpus spp., Pylaiella littoralis (L.) Kjellm. and Elachista sp. [18]. The edible Hijiki (Sargassum fusiforme (Harvey) Setchell), Kombu (Saccharina japonica (Aresch.) C.E. Lane, C. Mayes, Druehl \& G.W. Saunders) and dulse (Palmaria palmata (L.) F. Weber \& D. Mohr) have significant proportions of AsHCs of the total AsLs (20-50\%) [10, 19, 20]. Due to high amounts of iAs in Hijiki, its consumption has been discouraged for a number of years [5]. The cultivation of Saccharina latissima and Alaria esculenta has received significant attention as species for human consumption in Europe due to their potentially high biomass yields and nutrient content [21-23]. When considering human consumption, the blades are of highest interest since, e.g. when multiple partial harvest of cultivated seaweed is employed, the holdfast and stipe are left on the ropes [22]. Here we investigate if AsLs are uniformly distributed within the edible brown algal (kelp) species Saccharina latissima and Alaria esculenta which may provide clues to where these species are formed or stored.

\section{Materials and methods}

\section{Chemicals and materials}

All materials used were of analytical grade or better unless otherwise stated. MilliQ ( $18 \mathrm{M} \Omega \mathrm{cm})$ water was used throughout. A $1000 \mathrm{mgL}^{-1}$ As stock solution (as $\mathrm{H}_{3} \mathrm{AsO}_{4}$ ) was purchased from Peak Performance (CPI International, USA) as were Te $\left(1000 \mathrm{mgL}^{-1}\right)$ and $\mathrm{In}\left(1000 \mathrm{mgL}^{-1}\right)$ standards for use as internal standards, for calibration of arsenic species. Dimethylarsinic acid disodium salt (100\%) supplied by Argus-Chemicals (Italy) was dissolved in MilliQ water and diluted as required. Disodium methyl arsonate hexahydrate (99.5\%) was supplied by Chem-Service (USA); disodium hydrogen arsenate heptahydrate $\left(\mathrm{As}^{\mathrm{V}}\right)$, sodium arsenite $\left(\mathrm{As}^{\mathrm{III}}\right)$ and ammonium carbonate were purchased from BDH (UK). Chemicals used for extractions were purchased from SigmaAldrich: $\mathrm{MeOH}$ (> 99.9\%), DCM (> 99.8\%), hexane (>97\%). Hydrogen peroxide (puriss p.a., $>30 \%$ ) was also purchased from Sigma-Aldrich. Two nitric acids were used: trace select $(>69 \%$ ) was purchased from Fluka (UK) and puriss p.a. (> $65 \%$ ) was purchased from Sigma-Aldrich; the puriss p.a. acid was used throughout unless otherwise stated.

\section{Sample collection and preparation}

Samples of seaweed were collected from the northern coast of the Reykjanes peninsula in the southwest region of Iceland (January 2017). Approximately $1.5 \mathrm{~kg}$ of Saccharina latissima (L.) C.E. Lane, C. Mayes, Druehl \& G.W. Saunders (30-40 individuals) and $500 \mathrm{~g}$ of Alaria esculenta (L.) Grev. (15-20 individuals), both Phaeophyceae (Ochrophyta), were collected ensuring that the holdfast was taken as intact as possible. A lower mass of A. esculenta was collected as the individual samples were smaller than S. latissima, and A. esculenta grows at a lower shore level, making it less accessible for sampling. The seaweed was transported back to the lab in plastic bags and stored overnight in a fridge at $4{ }^{\circ} \mathrm{C}$. The seaweed material was then manually cleaned of epiphytes, epizoa and detritus with the aid of tap water. The cleaned samples were then rinsed with MilliQ water and cut into sections which were pooled together for all samples of each species, Fig. 1, and subsequently freeze-dried and ground to a fine powder.

As in other kelps, meristematic growth of S. latissima occurs at the base of the frond, with the youngest region closest to the stipe. The old frond may be damaged by wave action and other environmental stressors, and decay can be particularly pronounced during summer when growth is slowest. S. latissima samples were divided into holdfast, stipe, young frond, sori-containing frond sections and old fronds. The distinction between 'old' frond and 'young' frond was determined as the point where the frond narrowed; this was apparent on all samples and is purported to be caused by the reduced growth rate over the summer period. Sori of S. latissima were identified as visibly darker areas on the frond located in the centre of the frond and checked for the presence of sporangia. The presence of sori in S. latissima is seasonal and generally restricted to autumn and winter periods; their presence hence indicates recently produced material within the old frond. Where individuals did not have visible sori present, they were divided into the other four sections specified above. All other sections were present and easily identified in all individuals, however, the relative size of the old and young fronds varied by 
Fig. 1 Diagram of sections cut from a Saccharina latissima and b Alaria esculenta.

Figures adapted from [24]
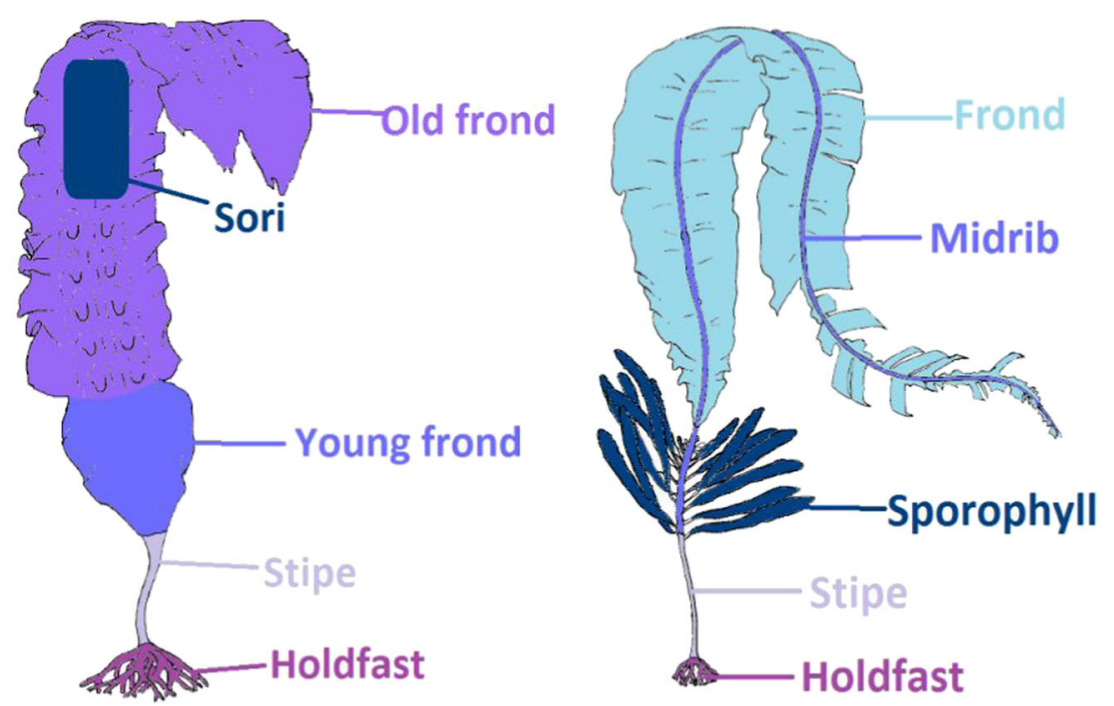

individual. The pooled individuals differed in size; hence, they were likely of different ages or represented different developmental stages.

Specimens of A. esculenta were divided into the following sections: holdfast, stipe, sporophyll (thick leafy pods growing on the stipe containing sporangia), midrib and frond. All sections were present and easily identifiable in all individuals. The distinction between stipe and midrib was taken to be just below the sporophylls and care was taken to cleanly separate the frond from the midrib.

\section{Sample preparation}

Total arsenic One hundred to $200 \mathrm{mg}$ of seaweed (triplicate) was accurately weighed in XP1500 vessels; $3 \mathrm{~mL}$ nitric acid (trace select) was added and left overnight; subsequently, hydrogen peroxide $(1.5 \mathrm{~mL})$ was added before microwave digestion (MARS 5, CEM) with a temperature program of $10 \mathrm{~min}$ ramp to $200^{\circ}$ and held for $8 \mathrm{~min}$. After digestion, the samples were diluted to $30 \mathrm{~mL}$ in MilliQ water [25]. The samples were stored in a freezer at $-18{ }^{\circ} \mathrm{C}$ until the day of analysis when they were further diluted by a factor of 4 .

Sequential extraction of arsenic species Sequential extraction was carried out to gain a mass balance of the arsenic species [19]. Sequential extraction also serves a purpose when AsLs are to be identified by organic mass spectrometry, since otherwise the signals of the AsLs may be masked under signals from other compounds. Further, it removes certain compounds which would not elute from the chosen HPLC column. Approximately 500-600 mg of seaweed (duplicate) was accurately weighed into glass vials $(20 \mathrm{~mL})$. Step 1: The seaweed was extracted in $2 \times 5 \mathrm{ml}$ of hexane (left to stand for 3 and $0.5 \mathrm{~h}$ ). The supernatants were combined and evaporated to dryness (hexane fraction). Step 2: The dry seaweed residue was subsequently extracted in $2 \times 5 \mathrm{~mL}$ of $\mathrm{DCM} / \mathrm{MeOH}$ (2:1), gently shaken until the sample was suspended in the solution and left to stand overnight (30 min for second extraction), supernatants combined and evaporated to dryness (MeOH fraction). Step 3: The residue was extracted in $15 \mathrm{~mL}$ of water (in plastic vials) and shaken thoroughly and left overnight to extract. Samples centrifuged at $3500 \mathrm{rpm}$ for $10 \mathrm{~min}$ and the supernatant was removed (water fraction). Step 4: The residue was washed with $2 \times 10 \mathrm{~mL}$ aliquots of water (as discussed in detail in Pétursdóttir et al. [19]) prior to drying in oven $\left(60^{\circ} \mathrm{C}\right)$. A subsample of the residue $(\sim 250 \mathrm{mg})$ was left overnight in $1 \mathrm{~mL}$ acid in the digestion vessel (XP1500) and $1.5 \mathrm{~mL} \mathrm{H}_{2} \mathrm{O}_{2}$ was added prior to microwave digestion. The samples were diluted to $10 \mathrm{~mL}$ with MilliQ water (residue).

These four fractions represent the non-polar AsLs (hexane), the polar AsLs (MeOH fraction), the water-soluble arsenicals (water fraction) and non-extractable arsenic left in the residue. These fractions should account for the total arsenic giving further confidence in the quantification methods of the AsLs. The AsLs investigated with speciation analysis in addition to total As of the fraction were in the $\mathrm{DCM} / \mathrm{MeOH}$ fraction.

Preparation for total As and As speciation analyses after sequential extraction The hexane fraction from step 1 was redissolved in approx. $1 \mathrm{~mL}$ hexane and transferred to digestion bombs and evaporated before microwave digestion ( $1 \mathrm{~mL}$ of nitric acid and $1.5 \mathrm{~mL}$ hydrogen peroxide diluted to $10 \mathrm{~mL}$ after microwaving). The $\mathrm{MeOH}$ fraction from step 2 was re-dissolved in $\mathrm{MeOH}$ (approx. $1 \mathrm{~mL}$ ) and transferred to pre-weighed HPLC vials. One subsample $(100 \mu \mathrm{L})$ was taken for microwave digestion for total arsenic measurement ( $3 \mathrm{~mL}$ of nitric acid and $1.5 \mathrm{~mL}$ hydrogen peroxide, diluted to $30 \mathrm{~mL})$. A second subsample was taken $(300 \mu \mathrm{l})$ and centrifuged at $13000 \mathrm{rpm}$ for $5 \mathrm{~min}$ on the day of speciation analysis (HPLC condition A). One millilitre of the 
water fraction from step 3 was digested $\left(1 \mathrm{~mL} \mathrm{HNO}_{3}\right.$, $1.5 \mathrm{~mL} \mathrm{H}_{2} \mathrm{O}_{2}$ ) and diluted to $10 \mathrm{~mL}$.

This sequential extraction was repeated, where the main difference was an hour of mechanical shaking that was added before each extraction steps $1-3$. The subsample of the $\mathrm{MeOH}$ fraction was transferred to an HPLC vial and evaporated to dryness under $\mathrm{N}_{2}$ and shipped dry under $\mathrm{N}_{2}$ to the University of Aberdeen for speciation analysis (HPLC condition B). The samples were shipped dry under $\mathrm{N}_{2}$ as it is the authors' experience that the AsPLs are more stable when stored dry, although this has not been quantified. These sample preparations were carried out in single replicates due to limited sample material for some sections and time-consuming instrumental analysis. Additionally, triplicates were prepared for 1 sample of A. esculenta and 1 sample of S. latissima to estimate the reproducibility.

Extraction of arsenosugars One hundred milligrams of each seaweed sample (triplicate) was accurately weighed into $50-\mathrm{mL}$ plastic vials and shaken thoroughly with $10 \mathrm{~mL}$ of water and left overnight, samples were centrifuged (3000 rpm for $10 \mathrm{~min}$ ) and the supernatant (AsSugar extract) was then transferred to a $15-\mathrm{mL}$ vial (Sarstaedt). On the day of measurement, $500 \mu \mathrm{l}$ of each AsSugar extract was transferred to plastic Eppendorf vials and centrifuged at $13000 \mathrm{rpm}$ for $5 \mathrm{~min}$. The supernatant was then transferred to a plastic HPLC vial.

\section{Analysis}

\section{Instrumental setup and analysis}

The ICP-MS was optimised daily for sensitivity and stability. ICP-MS Agilent 7500ce and 1200 Agilent HPLC were used for all measurements except for speciation of AsLs with condition B.

Total arsenic Samples were analysed in no gas and He mode (1500 W). Monitored masses were $\mathrm{m} / \mathrm{z} 75$ for As, internal standards (IS) $\mathrm{m} / \mathrm{z} 125$ for Te (50 ppb), $\mathrm{m} / \mathrm{z} 115$ for In $(2 \mathrm{ppb})$, and the possible chloride interference $\left(40 \mathrm{Ar} 35 \mathrm{Cl}^{+}\right)$

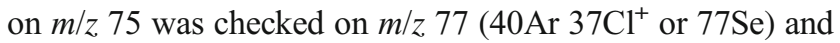
on $m / z, 82$ (82Se). An external calibration was used for the quantification of total arsenic (beginning and end of each run) and an intermediate standard was repeated throughout the analysis. A blank was analysed between each set of triplicates.

\section{Speciation AsLs}

A) A C18 HPLC column (Agilent Eclipse XDB C18 $5 \mu \mathrm{m}, 4.6 \times 150 \mathrm{~mm}$ ) was used to achieve separation of the compounds during speciation analysis $(\mathrm{MeOH}$ fraction), and a flow splitter (3:1, 3 parts waste, 1 part ICP-MS) was used to reduce the volume of solvent entering the spray chamber. An internal standard of Tellurium (50 ppb) and Ge (2 ppb) was added online between flow splitter and ICP-MS to monitor instrument stability. A response factor was calculated by switching to an internal standard containing DMA (50 ppb) and Te (50 ppb) and Ge (2 ppb), injecting a blank and monitoring the measured As intensity over the course of the run as described in Amayo et al. [26]. Quantification was carried out using Ge as IS. Standards were prepared by diluting dimethyl arsenic in water and were analysed before and in the middle of the sample sequence. HPLC gradient program and parameters were specifically optimised for separation on the ICPMS 7500ce (not shown). Sample injection volume was $30 \mu \mathrm{L}, 1 \mathrm{~mL} \mathrm{~min}^{-1}$ flow rate using a gradient program $20 \mathrm{~min} 70-100 \%$ B hold for $20 \mathrm{~min}$. Eluent $\mathrm{A}$ is $0.1 \% \mathrm{FA}$ in $\mathrm{H}_{2} \mathrm{O}$, and eluent $\mathrm{B}$ is $0.1 \%$ $\mathrm{FA}$ in $\mathrm{MeOH}$, with the ICP-MS in organic mode $(1530 \mathrm{~W})$, with platinum cones and $14 \%$ oxygen.

B) HPLC (Agilent 1290) coupled to Agilent 8800 (QQQ) ICPMS. Same column as in A, injection volume $0.1 \mathrm{~mL}$, flow $1 \mathrm{~mL} \min ^{-1}$, gradient $0-20 \mathrm{~min}: 0-100 \% \mathrm{~B}$, hold 25 min (eluents same as in A). Flow split post column 3:1, 3 parts to ESI-MS (LTQ Orbitrap Discovery; Thermo Scientific) and 1 part to ICP-MS. Agilent 8800 (QQQ) was used in organic mode with platinum cones and $6 \%$ optional oxygen. The As75 was analysed in oxygen mode on $\mathrm{m} / \mathrm{z}$ 91, other masses monitored, P31, S32 and Ge74. The ESI-MS was operated in positive mode with a scan range of $m / z, 100-1300$. Other parameters for the Orbitrap were $4.5 \mathrm{kV}$ spray voltage, $35 \%$ normalised collision energy, $300{ }^{\circ} \mathrm{C}$ capillary temperature and $42 \mathrm{~V}$ capillary voltage with a resolution of 30.000 for MS and MSMS spectra. Parameters are similar to Petursdottir et al. [18].

Arsenolipid identification Identification was carried out by searching for known AsL masses (Thermo, Excalibur) and matching the found $m / z$ for the individual AsLs with the signal from the ICP-MS ( $m / z$ 75), Fig. 3. Only the major peaks had corresponding $\mathrm{MS}^{2}$ data. Acceptable $\Delta m / z$ (ppm) was taken at 2 ppm, but peaks under 3 ppm are also shown, Table 3 .

AsSugars Strong anion column (Hamilton PRPX-100 10 um $250 \times 4.1 \mathrm{~mm}$ ) with $1 \mathrm{~mL} \mathrm{~min}^{-1}$ of mobile phase ammonium carbonate $(30 \mathrm{mM}, \mathrm{pH} 9)$ was used for the AsSugar analysis. ICPMS is in no gas mode $(1500 \mathrm{~W})$; masses monitored are as follows: $m / z 75$ for As, $m / z, 125$ for Te (50 ppb), $m / z 115$ for In (2 ppb), $m / z, 77$ and $m / z, 82$ [18]. 


\section{Results and discussion}

\section{Quality control}

Certified reference materials (CRM) Hijiki NMIJ 7405-a $(n=$ 12) and Tort-2 (Lobster Hepatopancreas) $(n=9)$ were digested and measured for totAs with each measurement showing good agreement with certified values: $22.1 \pm 1.8 \mathrm{mg} \mathrm{kg}^{-1}$ for TORT-2 (cert. $21.6 \pm 1.8 \mathrm{mg} \mathrm{kg}^{-1}$ ) and $35.9 \pm 3.4 \mathrm{mg} \mathrm{kg}^{-1}$ for Hijiki (cert. $35.8 \pm 0.9 \mathrm{mg} \mathrm{kg}^{-1}$ ). Hijiki (7405-a) was extracted alongside the samples during the sequential extractions and AsSugar extraction to monitor the extraction efficiency. The mass balance for Hijiki was in good agreement with the certified totAs in the sample, or 92-104\%, Table 1. LOD and LOQ were calculated as $3 \times$ and $10 \times$ SD of blank samples, respectively, where an average dilution factor was used to convert to concentration in sample.

\section{Total arsenic and mass balance}

The total arsenic of each step of the sequential extraction was measured for totAs to account for the mass balance of the method. The sum of all four steps (hexane, $\mathrm{MeOH} / \mathrm{DCM}$, water, residue) showed good agreement with the totAs in the seaweed where the recovery ranged generally from 78 to $115 \%$; an exception was the sori where the recovery was higher (139\%), Table 1, most likely due to overestimation of the water and residue fractions. The amount of arsenic in the hexane fraction seemed more arbitrary than in the other fractions, ranging from very little non-polar As present to up to $1 \mathrm{mg} \mathrm{kg}^{-1}$. CRM Hijiki has been reported before with reasonable agreement with the totAs for the $\mathrm{MeOH} / \mathrm{DCM}$ phase at $6.24 \mathrm{mg} \mathrm{kg}^{-1}$ [20] and $3.8 \mathrm{mg} \mathrm{kg}^{-1}$ [27] compared to $7.9 \mathrm{mg} \mathrm{kg}^{-1}$ here on average, Table 1. The lower value reported by Wolle et al. [27] for the $\mathrm{MeOH} / \mathrm{DCM}$ phase is likely due to a water extraction prior to the $\mathrm{MeOH} / \mathrm{DCM}$ as reported in Pétursdóttir [19] and also speculated by Wolle et al. [27]. The totAs for the hexane fraction [20] was higher than found here, or $0.97 \mathrm{mg} \mathrm{kg}^{-1}$ compared to $0.1 \mathrm{mg} \mathrm{kg}^{-1}$. Total As of water-soluble fraction of hijiki was in good agreement at $22.6 \mathrm{mg} \mathrm{kg}^{-1}$ [27] compared to $20 \pm$ $2 \mathrm{mg} \mathrm{kg}^{-1}$ found here, Table 1 .

The total arsenic was measured for each section of the two seaweed species; there was a trend for concentrations in stipe and/or midrib to be only half of those observed in the other seaweed parts, Table 1, indicating that less arsenic is stored within the stipe than other parts of the seaweed.

For S. latissima, the highest amount of non-polar As was present in the sori and the young frond, but for A. esculenta, in

Table 1 Total arsenic of each fraction and the total arsenic of the different seaweed sections in milligrams/kilogram. Short names for Saccharina latissima starts with SL and for Alaria esculenta with AE

\begin{tabular}{|c|c|c|c|c|c|c|c|c|c|c|}
\hline Short name & Section & Batch & $n$ & Hexane & $\mathrm{MeOH}$ & Water & Residue & Sum & Total As & $\%$ recovery \\
\hline \multirow[t]{2}{*}{ SLOF } & \multirow[t]{2}{*}{ Old frond } & $\mathrm{a}$ & 2 & $<\mathrm{LOQ}$ & $7.7 \pm 0.2$ & $95 \pm 9$ & $11.8 \pm 0.8$ & $114 \pm 8$ & $117 \pm 9$ & 97 \\
\hline & & $\mathrm{b}$ & 3 & $0.49 \pm 0.04$ & $8.4 \pm 0.6$ & $97 \pm 2$ & $10.4 \pm 0.7$ & $116 \pm 2$ & & 98 \\
\hline \multirow[t]{2}{*}{ SLYF } & \multirow[t]{2}{*}{ Young frond } & $\mathrm{a}$ & 2 & $0.4 \pm 0.1$ & $8.8 \pm 0.5$ & $73 \pm 3$ & $45 \pm 8$ & $128 \pm 11$ & $116 \pm 6$ & 110 \\
\hline & & $\mathrm{b}$ & 1 & 0.45 & 12.0 & 90.9 & 23.6 & 126.9 & & 110 \\
\hline \multirow[t]{2}{*}{ SLSP } & \multirow[t]{2}{*}{ Sori } & $\mathrm{a}$ & 2 & 0.7 & $11 \pm 1$ & $126 \pm 6$ & $21 \pm 11$ & $159 \pm 5$ & $114 \pm 28$ & 139 \\
\hline & & $\mathrm{b}$ & 1 & 1.1 & 12.5 & 109.6 & 5.6 & 128.8 & & 113 \\
\hline \multirow[t]{2}{*}{ SLHF } & \multirow[t]{2}{*}{ Holdfast } & $\mathrm{a}$ & 2 & $<\mathrm{LOQ}$ & $5.2 \pm 0.4$ & $94 \pm 9$ & $11 \pm 1$ & $110 \pm 8$ & $127 \pm 6$ & 87 \\
\hline & & $\mathrm{b}$ & 1 & 0.11 & 6.0 & 112.4 & 9.3 & 127.8 & & 101 \\
\hline \multirow[t]{2}{*}{ SLS } & \multirow[t]{2}{*}{ Stipe } & $\mathrm{a}$ & 2 & $<$ LOQ & $2.9 \pm 0.3$ & $40.1 \pm 0.1$ & $8 \pm 1$ & $51 \pm 1$ & $53 \pm 5$ & 97 \\
\hline & & $\mathrm{b}$ & 1 & 0.03 & 4.8 & 36.7 & 6.8 & 48.3 & & 91 \\
\hline \multirow[t]{2}{*}{ AES } & \multirow[t]{2}{*}{ Stipe } & $\mathrm{a}$ & 2 & $0.38 \pm 0.03$ & $3.7 \pm 0.5$ & $33.3 \pm 0.1$ & $4.1 \pm 0.3$ & $41.4 \pm 0.4$ & $53 \pm 3$ & 78 \\
\hline & & $\mathrm{b}$ & 1 & 0.15 & 6.5 & 31.4 & 4.5 & 42.5 & & 80 \\
\hline \multirow[t]{2}{*}{ AEMR } & \multirow[t]{2}{*}{ Midrib } & $\mathrm{a}$ & 2 & $0.48 \pm 0.03$ & $4.1 \pm 0.2$ & $30 \pm 2$ & $9.6 \pm 0.6$ & $46 \pm 2$ & $43 \pm 4$ & 104 \\
\hline & & $\mathrm{b}$ & 3 & $0.33 \pm 0.17$ & $4.1 \pm 0.2$ & $29 \pm 1$ & $6.0 \pm 0.5$ & 39.4 & & 92 \\
\hline \multirow[t]{2}{*}{ AESP } & \multirow[t]{2}{*}{ Sporophyll } & $\mathrm{a}$ & 2 & $0.4 \pm 0.4$ & $8.0 \pm 0.6$ & $102 \pm 3$ & $12 \pm 2$ & $128 \pm 4$ & $116 \pm 6$ & 106 \\
\hline & & $\mathrm{b}$ & 1 & 0.11 & 13.2 & 92.7 & 6.4 & 112.4 & & 97 \\
\hline \multirow[t]{2}{*}{ AEHF } & \multirow[t]{2}{*}{ Holdfast } & $\mathrm{a}$ & 2 & $0.03 \pm 0.02$ & $7.3 \pm 0.6$ & $82 \pm 4$ & $6 \pm 2$ & $96 \pm 3$ & $102 \pm 2$ & 94 \\
\hline & & $\mathrm{b}$ & 1 & 0.78 & 8.7 & 80.1 & 5.1 & 94.7 & & 93 \\
\hline \multirow[t]{2}{*}{ AEF } & \multirow[t]{2}{*}{ Frond } & a & 2 & 0.70 & $4.0 \pm 0.1$ & $85 \pm 5$ & $16 \pm 1$ & $106 \pm 6$ & $93 \pm 4$ & 115 \\
\hline & & $\mathrm{b}$ & 1 & 0.56 & 4.6 & 64.4 & 10.9 & 80.4 & & 87 \\
\hline \multirow[t]{2}{*}{ Hijiki } & \multirow[t]{2}{*}{ Hijiki } & a & 2 & LOQ & $5.6 \pm 0.3$ & $20 \pm 1$ & $7.1 \pm 0.1$ & $33 \pm 1$ & 35.6 & 92 \\
\hline & & $\mathrm{b}$ & 2 & $0.10 \pm 0.01$ & $10.1 \pm 0.7$ & $20 \pm 2$ & $6.8 \pm 1.0$ & $37 \pm 2$ & & 104 \\
\hline
\end{tabular}

LOD $0.005 \mathrm{mg} \mathrm{kg}^{-1}$, LOQ $0.02 \mathrm{mg} \mathrm{kg}^{-1}$ 
the frond and midrib. The samples were extracted in two batches prepared and analysed on separate days; in general, batch $\mathrm{A}$ extracted less of polar As than batch $\mathrm{B}$, where mechanical shaking for batch B may have contributed to the better extraction. There was more As in the residue for batch A. Most likely, the sample residue was not rinsed well enough before drying; hence, any remaining As from the previous step (water extraction) could lead to an overestimation. In general, there was good consensus on the batches showing good repeatability, Table 1 .

\section{Arsenolipids}

When the samples were collected and sectioned, the working hypothesis was that seaweed parts differed not only in age, but also in biological function or developmental stage and therefore differences in the AsL composition could be expected. Previously, it had been shown, for example, that alginate composition varied by tissue type reflecting the different biological functions [28]. These findings influenced how the algae were sectioned in this study. Both holdfast and stipe (functions:

a

a 2.5

Stipe

- Holdfast

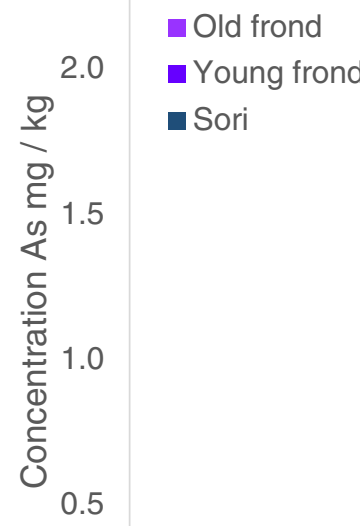

0.0 -

U

I

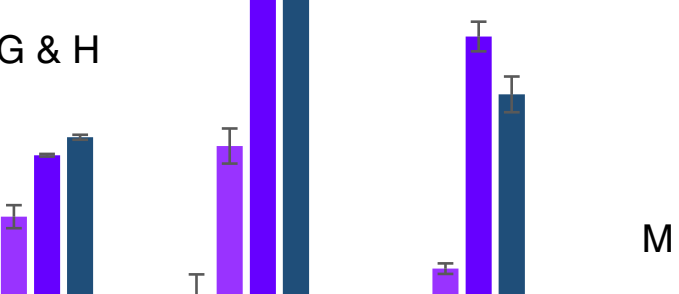

AsHC

AsHC

AsPL1014

b
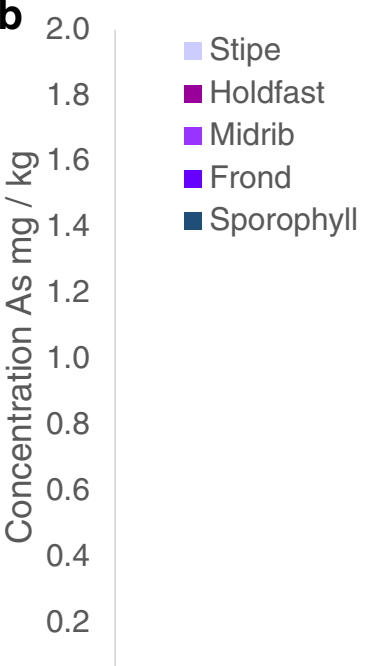

0.0

AsHC
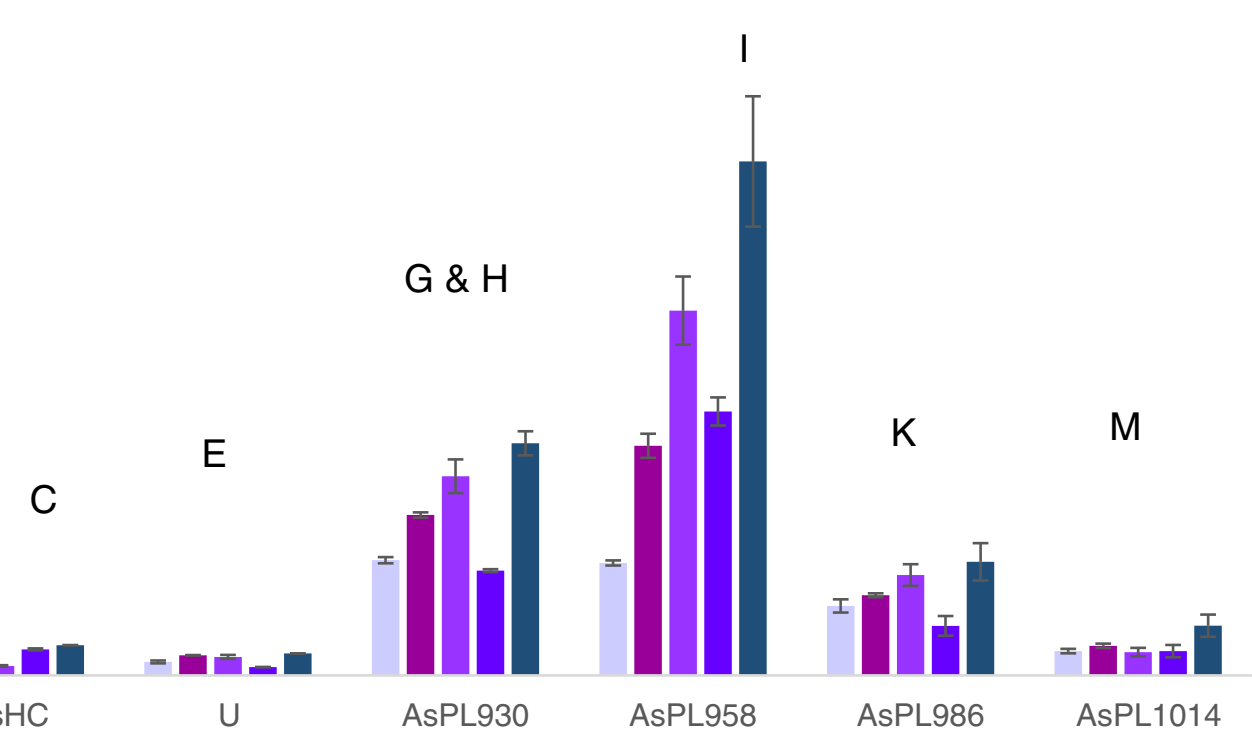

Fig. 2 Quantification of AsLs (batch A) for a Saccharina latissima and b Alaria esculenta. Quantification is given in ESI. Letters correspond to equivalent peaks in batch B (e.g. Fig. 3). The major AsL per each peak is given 
anchorage/attachment and support, respectively) of $S$. latissima represented older and more rigid structures, while the blade is renewed on an annual basis. However, holdfasts contained a visible mixture of both old and newly produced rhizoids entwined together. The stipe also contained younger growth since the inner part of the stipe is older and the outer part is younger. The internal profile of the stipe and holdfast was not investigated since for this, e.g. bioimaging would be needed; However, as kelp stipe and holdfasts have distinct functions, their chemistry, in particular their alginate composition, is likely to differ, and is additionally influenced by season and environment [[28], [29, 30]]. The frond was clearly divided into older and newer sections, with an age gradient along the blade and youngest parts towards the stipe, and oldest towards the blade tip. The sori, produced seasonally, represented reproductive materials and were visibly different as a dark patch containing sporangia. Therefore, a distinction was made both for age and metabolic function of the frond. The first results from the $\mathrm{MeOH}$ fraction (batch A) showed a significant difference between the different seaweed segments. By ordering the segments by age, function or reproductive stage, an increasing trend can be observed, which is especially pronounced for S. latissima with younger or reproducibly active tissue containing some of the AsSugPLs in significant higher amounts than older thallus parts. A. esculenta also contains more AsLs in the reproductive tissue than elsewhere, Fig. 2.

The ESI-MS analysis was performed a week later than the quantification and due differences in the retention times only the main AsPLs could be assigned based on data from CRM hijiki (see Electronic Supplementary Material (ESM) Section 2). The AsPL do not appear to be stable with time; hence only the most abundant were still present in the samples. The sample preparation was repeated (batch B) and measured the second time with simultaneous HPLC-ICP-MS/ESIMS for reliable and accurate identification of AsLs. This allowed for the verification of the quantification and the noticed trend (ESM Section 5). Even though the concentration of the AsLs was lower for the first batch of samples, the increasing trend of AsPL with 'activity' was seen for the main AsPLs in S. latissima, although the trend was not noticeable for the heavier AsPLs. This may be due to their lower concentration, or potentially they are less stable, ESM Fig. S11. The quantification for the A. esculenta indicates a similar trend for the AsPLs but the results were more ambiguous due to instrumental problems (ESM Section 5).

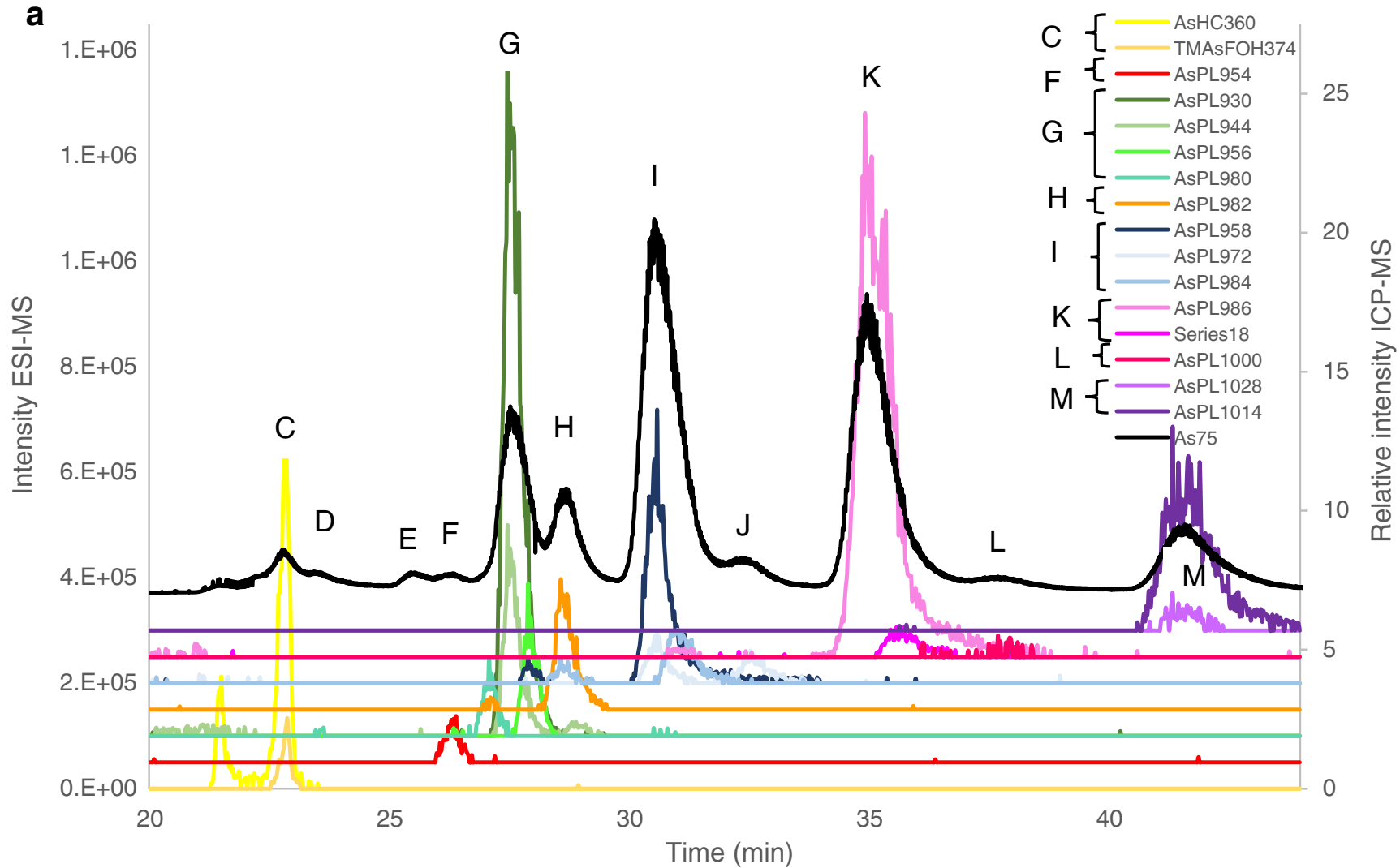

Fig. 3 Overlay of ESI-MS data (coloured lines) and ICP-MS (black, $\mathrm{m} / \mathrm{z}$ 75) for a Saccharina latissima young frond, b Alaria esculenta midrib and $\mathbf{c}$ Hijiki CRM 7405a. There was a minor time delay for the ESI-MS data and to compensate this, the ICP-MS signal was shifted to a $0.7-0.9$ min earlier retention time for all chromatographs. Magnification of closeeluting peaks distinguished with ESI-MS is shown in ESM Fig. S5 


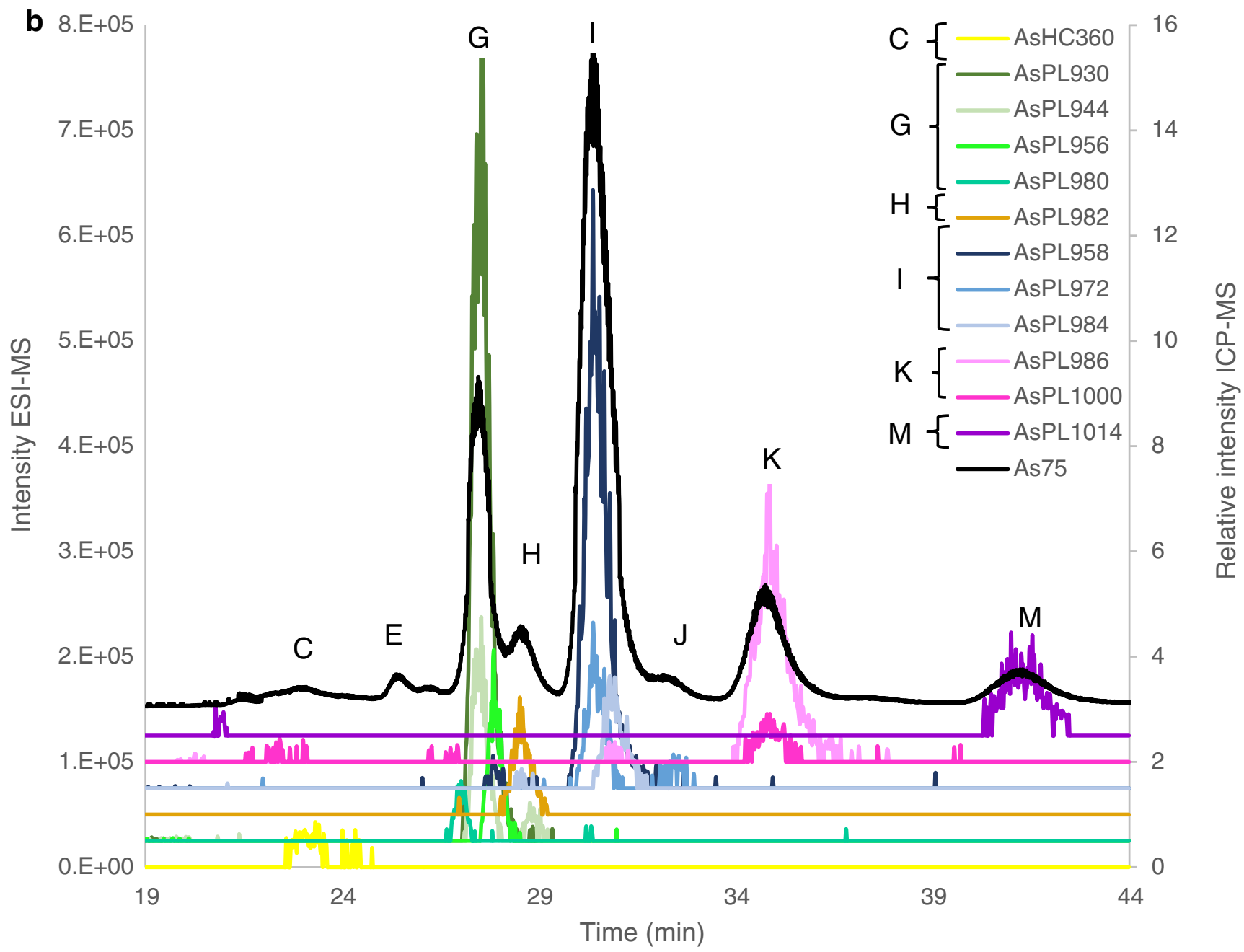

Fig. 3 (continued)

Quantification for both batches was in good agreement with the totAs of the extracts, where the column recovery was $96 \pm 11 \%$ and $85 \pm 11 \%$ for batches A and B, respectively. CRM NMIJ 7405-a (Hijiki) was analysed with all AsL measurements. Hijiki is not certified for AsLs but Glabonjat et al. [20] report identification of 7 AsLs. The two AsHCs identified (AsHC332-1.07 $\pm 0.04 \mathrm{mg} \mathrm{kg}^{-1}$, AsHC360-0.090 \pm $0.005 \mathrm{mg} \mathrm{kg}^{-1}$ ) in their work are in good agreement with the main AsHC identified here (AsHC332 major, AsHC360 minor, TMAsFOH minor, other AsHCs traces), Fig. 3c. Batch A showed good agreement with the quantification (1.11 \pm $0.05 \mathrm{mg} \mathrm{kg}^{-1}$ ) for the AsHCs but batch B had higher concentrations $\left(2.0 \pm 0.1 \mathrm{mg} \mathrm{kg}^{-1}\right)$, Table 2. The peak pattern for AsPLs is similar, Fig. 3c, as reported by Glabonjat et al. [20] (AsPL958 (here peak I) $1.59 \pm 0.03$, AsPL986 (here peak K) $0.304 \pm 0.006$, AsPL1014 (here peak M) 0.21 \pm 0.01 , AsPL1042 0.114 \pm 0.003 , AsPL1070 0.043 \pm 0.002 ), although the two heavier AsPLs were not found here due to the chromatograph being cut short before their elution.
Quantification for peaks $\mathrm{K}$ and $\mathrm{M}$ was in good agreement with the reported values for AsPL986 and 1014, Table 2; however, peak I contained higher concentration than reported for the AsPL958. Additionally, to these main 3 AsPLs, a more diverse flora of AsPLs were either identified here as minor components or found as traces, Fig. 3c.

Results of S. latissima (from Scotland) reported in Raab et al. [7] were in good agreement with regard to the AsLs identified with the addition of AsPL954, AsPL1012 and AsPL1028 found here. The AsHCs and AsFAs were the same as those identified by Raab et al. [7] except for AsHC388 which was only found here in $A$. esculenta not $S$. latissima. The AsFAs are found in such trace amounts that there is not a peak found at $m / z, 75$ with the ICP-MS (ESM Fig. S3b). The similarity of AsLs found indicates that the AsL composition of As species in S. latissima varies little with location but the concentrations can vary more as the concentration of AsHCs is very low here unlike in Raab et al. [7]. Mono-acyl AsPLs are found at trace levels (mainly AsPL692 and AsPL720), ESM Table S1. These 


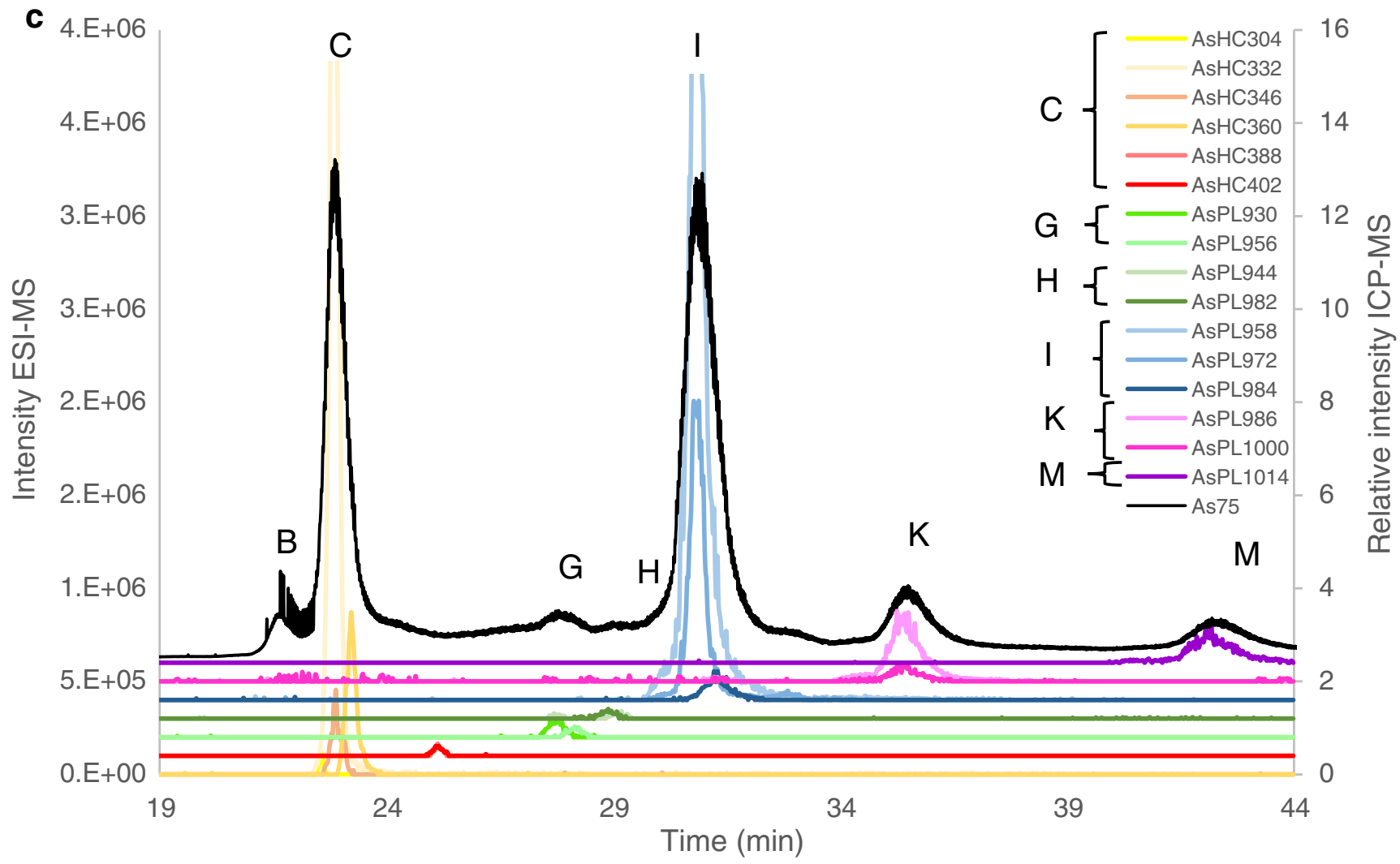

Fig. 3 (continued)

mono-acyl AsPLs (AsSugPLs) were identified in Kombu as a potential artefact resulting from the process of preparing the food product (sun-dried for days); however, they were also identified in fresh Kombu albeit at much lower concentrations [10]. Their presence here at trace levels (no MSMS data) indicates that they may be breakdown products from di-acyl AsPLs. This is supported by the fact that the mono-AsPLs identified here correspond with di-acyl AsPLs identified in the same samples, i.e. the two main mono-AsPLs (692 and 720) could be breakdown products of the two main AsPLs in

Table 2 Quantification of AsLs in Saccharina latissima and Alaria esculenta $\left(\mathrm{mg} \mathrm{kg}^{-1}\right)$, batch B (data for batch A in ESM) $n=1$ for all but hijiki $(n=$ 2), Saccharina latissima old frond and Alaria esculenta midrib $(n=3)$

\begin{tabular}{|c|c|c|c|c|c|c|c|c|c|c|c|c|c|}
\hline \multirow[b]{2}{*}{ Peak } & \multicolumn{6}{|c|}{ Saccharina latissima } & \multicolumn{5}{|c|}{ Alaria esculenta } & \multicolumn{2}{|c|}{ Hijiki } \\
\hline & $\mathrm{Rt}(\min )$ & Stipe & Holdfast & Old frond & Young frond & Sori & $\mathrm{Rt}(\min )$ & Stipe & Holdfast & Midrib & Sporophyll & Rt (m & in) \\
\hline A & 2.6 & 0.51 & 1.3 & $3.0 \pm 0.3$ & 3.3 & 4.1 & 2.5 & 3.0 & 4.9 & $0.80 \pm 0.03$ & 6.1 & 2.7 & $0.30 \pm 0.02$ \\
\hline \multirow[t]{2}{*}{ B } & 10.7 & & & LOQ & LOQ & & 10.2 & 0.072 & 0.070 & LOQ & 0.052 & & \\
\hline & & & & & & & 22.6 & 0.046 & 0.070 & & 0.087 & 22.6 & $0.30 \pm 0.06$ \\
\hline $\mathrm{C}$ & 23.8 & 0.12 & 0.17 & $0.34 \pm 0.02$ & 0.17 & 0.17 & 24.0 & 0.068 & 0.093 & $0.06 \pm 0.03$ & 0.18 & 23.8 & $2.0 \pm 0.1$ \\
\hline $\mathrm{D}$ & 25.5 & 0.072 & & $0.061 \pm 0.006$ & 0.066 & 0.077 & & & & & & & \\
\hline $\mathrm{E}$ & 26.4 & 0.063 & 0.043 & 0.053 & 0.056 & 0.045 & 26.5 & 0.089 & 0.10 & $0.06 \pm 0.01$ & 0.11 & & \\
\hline $\mathrm{F}$ & 27.2 & 0.051 & 0.049 & $0.047 \pm 0.008$ & 0.060 & 0.046 & 27.1 & & & $0.018 \pm 0.008$ & & & \\
\hline G & 28.6 & 0.47 & 0.36 & $0.70 \pm 0.09$ & 1.0 & 0.94 & 28.5 & 0.56 & 0.90 & $0.58 \pm 0.05$ & 0.80 & 28.7 & $0.17 \pm 0.04$ \\
\hline $\mathrm{H}$ & 29.7 & 0.20 & 0.26 & $0.41 \pm 0.03$ & 0.52 & 0.60 & 29.6 & & & $0.18 \pm 0.01$ & 0.31 & & \\
\hline I & 31.7 & 0.84 & 0.96 & $1.2 \pm 0.1$ & 2.5 & 2.2 & 31.7 & 0.70 & 1.2 & $1.3 \pm 0.2$ & 2.5 & 31.8 & $2.3 \pm 0.2$ \\
\hline $\mathrm{J}$ & 33.4 & 0.09 & 0.11 & $0.11 \pm 0.01$ & 0.17 & 0.17 & 33.2 & & & $0.06 \pm 0.01$ & & & \\
\hline K & 36.2 & 1.3 & 1.1 & $0.95 \pm 0.08$ & 1.9 & 1.3 & 35.8 & 0.40 & 0.53 & $0.35 \pm 0.01$ & 0.63 & 36.3 & $0.37 \pm 0.09$ \\
\hline $\mathrm{L}$ & 38.8 & 0.12 & 0.11 & $0.10 \pm 0.01$ & 0.064 & 0.10 & & & & & & & \\
\hline M & 43.0 & 0.47 & 0.34 & $0.30 \pm 0.02$ & 0.65 & 0.40 & 42.2 & 0.17 & 0.18 & $0.16 \pm 0.01$ & 0.31 & 43.1 & $0.20 \pm 0.03$ \\
\hline Sum & & 4.3 & 4.8 & 7.3 & 10.6 & 10.2 & & 4.8 & 8.7 & 3.6 & 12.4 & & 5.7 \\
\hline
\end{tabular}

LOD $0.009 \mathrm{mg} \mathrm{kg}^{-1}$, LOQ $0.03 \mathrm{mg} \mathrm{kg}^{-1}$ 


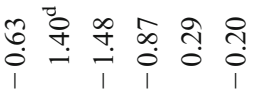

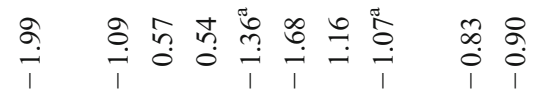

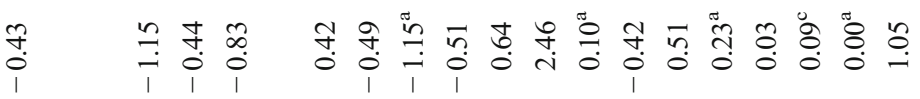

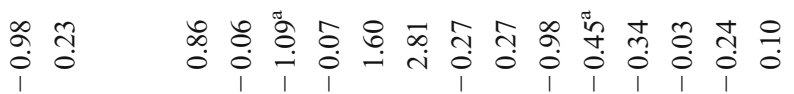

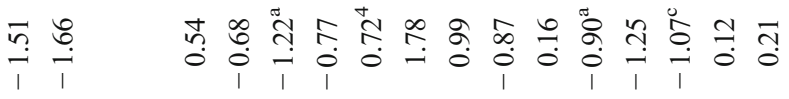

然

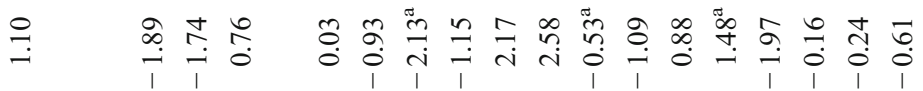

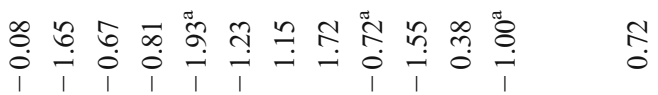

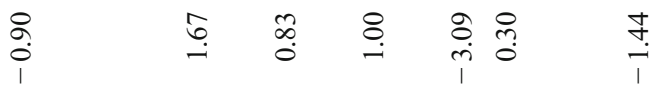

$\underset{i}{\infty}$

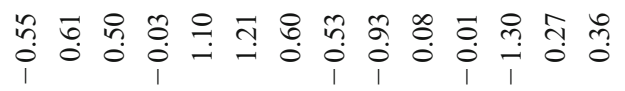

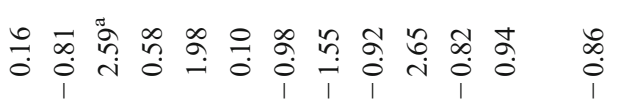

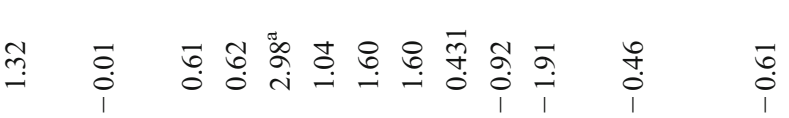

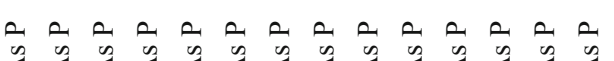

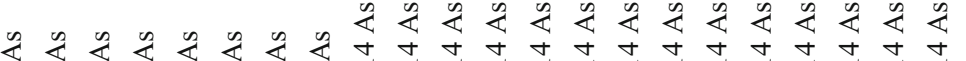

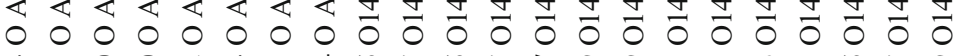

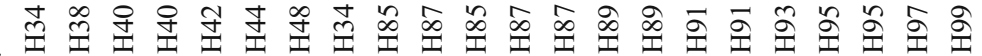

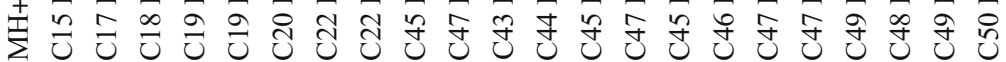

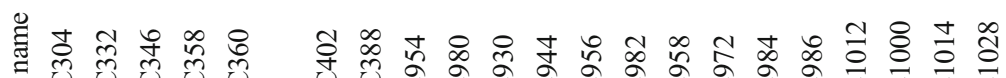

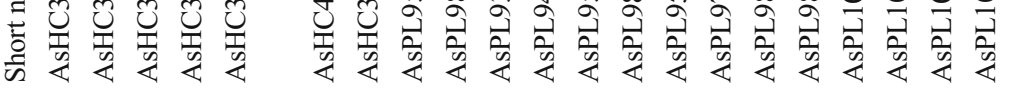
$\underset{\substack{0 \\ \frac{0}{0}}}{\frac{m}{\infty}}$

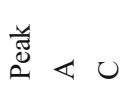
○ 
A. esculenta and S. latissima the AsPL930 and AsPL958, ESM Table S1. Fittingly, the AsPL692 was not present in hijiki, which did not contain AsPL930.

Only the most abundant AsL per peak had MSMS spectra (AsHC332, AsPL930, AsPL958, AsPL986, AsPL1014) where the most commonly found fragment ion for the AsPLs was 409.024 [7] Table 3. There was no MSMS data for $\mathrm{m} / \mathrm{z}$ 375.26; therefore, it is difficult to distinguish between the isomers TMAsFOH374 and AsHC374. The AsHC332, AsHC346, AsHC360 and AsHC374 are all saturated AsHCs that differ by 1 carbon in chain length where AsHC346 and AsHC360 elute with slightly different retention times but AsHC360 and $\mathrm{m} / \mathrm{z}$ 374 elute at the exact same time. This is in accordance with previous identification of TMAsFOH374 [12, 19]. This could indicate that the $\mathrm{m} / \mathrm{z}, 374$ is TMAsFOH374; however, AsHC332 and AsHC346 also elute at the exact time, and MSMS data reveals that $\mathrm{m} / \mathrm{z} 332$ is indeed AsHC332. The data are therefore not conclusive to confidently identify this minor species.

\section{Arsenosugars}

Samples were extracted in triplicate for AsSugar quantification and identification. The quantification showed a reasonably good column recovery $87 \pm 12 \%$ (range 62 $103 \%$ ). The main peaks in the samples were AsSugOH,

a

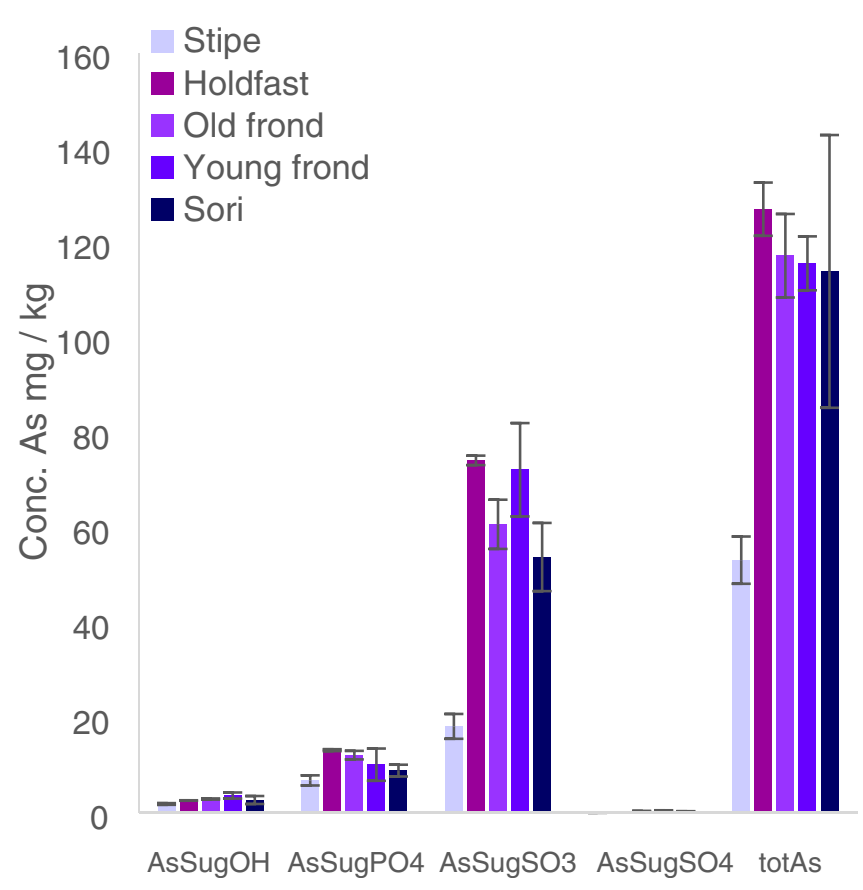

$\mathrm{AsSugPO}_{4}$ and $\mathrm{AsSugSO}_{3}$ in all samples, where other peaks were only minor (DMA, unknown and $\mathrm{AsSugSO}_{4} /$ AsV), ESM Tables S4-S6. Identification was based on an in-house reference material analysed in the same run as the samples. The identification of 4 main AsSugars (AsSugOH, AsSugPO 4 , AsSugSO $3, \mathrm{AsSugSO}_{4}$ ) had been previously done for this sample with LC-MS/MS (Thermo, Quantiva). Spiking of the samples also revealed the retention time of iAs and DMA. As(III) elutes with AsSugarOH and $\mathrm{As}(\mathrm{V})$ with $\mathrm{AsSugarSO}_{4}$. Low quantities of iAs were expected as, e.g. reported in Pétursdottir et al. [31] where the iAs was below $0.3 \mathrm{mg} \mathrm{kg}^{-1}$ in 10 samples of Icelandic $S$. latissima, and for the A. esculenta, the iAs cannot be significant since no peak was found at the Rt of $\mathrm{As}(\mathrm{V})$ and $\mathrm{AsSugSO}_{4}$ and small peaks at Rt for $\mathrm{As}(\mathrm{III})$ and AsSugarOH (Fig. 4b). Quantification of AsSugars in CRM Hijiki 7405a has been reported by Wolle et al. [27], showing good agreement with the quantification here, ESM Table S6, although double concentration of $\mathrm{AsSugarSO}_{3}$ was found here compared to Wolle et al., where this higher concentration may possibly be attributed to co-elution of other water-soluble species.

For the AsSugars, there was no noticeable trend in concentration based on the different sections of the seaweed except for the similarity of $\mathrm{AsSugSO}_{3}$ to the totAs, i.e. low conc. for stipe and midrib, and a much higher and similar concentration for all other parts of the seaweed, Fig. 4.

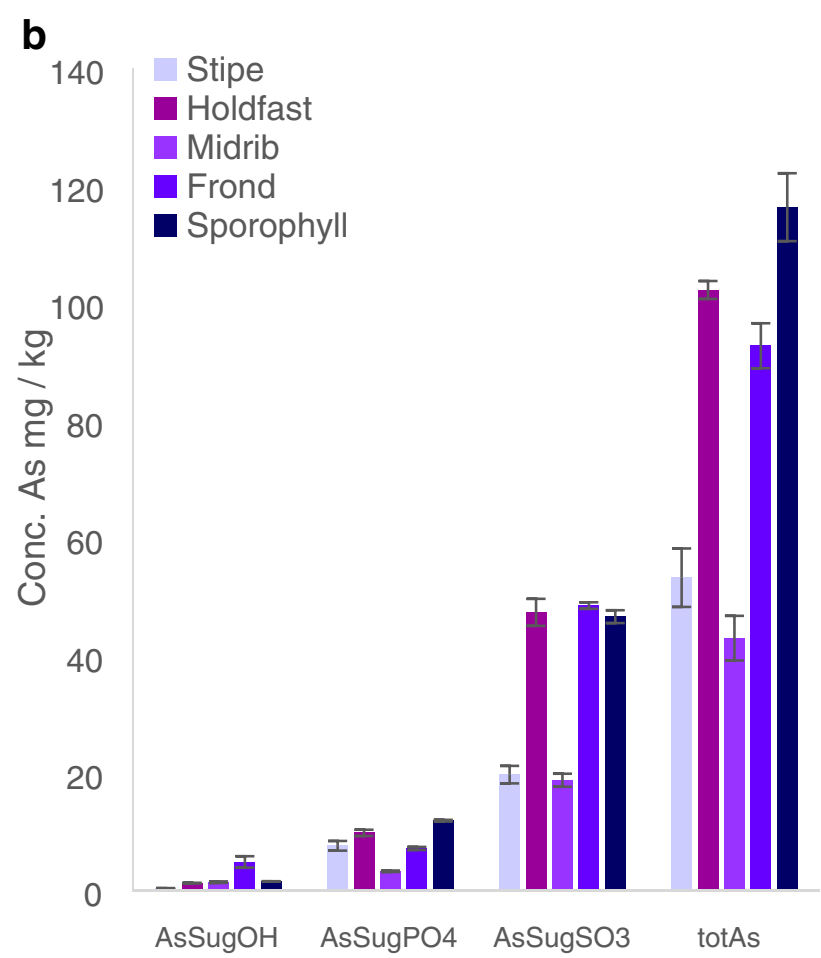

Fig. 4 AsSugars, other As trace peaks not shown, full quantification in ESM Tables S4 and S5. a Saccharina latissima. b Alaria esculenta 


\section{Conclusions}

In depth, arsenic speciation using parallel HPLC-ICP-MS/ ESIMS showed that both A. esculenta and S. latissima were very rich in AsLs, where the vast majority was in the form of diverse AsPLs. Very little was found as AsHCs, differing from hijiki which had approximately equal amounts of AsHCs and AsPLs. There are no toxicological data on AsPLs yet and these are urgently needed to better estimate the risk derived from, e.g. human consumption of seaweed.

Employing sophisticated speciation analyses further unravelled new information about AsLs in seaweed. Arsenic was not found to be uniformly distributed within the two brown macroalgal species, with lower levels of totAs found in the stipe/midrib compared to other thallus parts. This trend is mainly due to $\mathrm{AsSugSO}_{3}$ which was the most abundant As species in the two species. The AsLs however had a different distribution to the AsSugars or the totAs where the AsPLs differed by approx. a factor of 4 between the sections containing the lowest and highest concentration of AsPLs. When the sections were placed in order of estimated metabolic activity also incorporating an estimate of tissue age, taking into consideration within-blade variation and the fact that stipe and holdfast contained the oldest seaweed parts due to their perennial nature, there appeared to be a relationship between the metabolic activity and AsPLs, with lower levels of AsPLs in oldest parts. All seaweed materials had been collected at the time of the highest growth rates (late winter), and when newly formed patches of sori on S. latissima, and sporophylls on A. esculenta, were present. The data therefore suggest either that the two kelp species preferentially store the AsPLs in younger/metabolically active thallus parts, or that they were producing these AsPLs, possibly as a side product of a natural biological activity. Subsequently, since there is no evidence for a physiological requirement (or function) of these potentially toxic species, it seems they break down to AsSugars. This would suggest that AsPLs are formed before AsSugars or, alternatively, they are formed from AsSugars which undergo a temporary cycle to produce AsPLs. Currently, neither the sequence of biochemical processes involved, nor their potential biological relevance and energy requirements are clear.

Lai et al. [32] showed that different extraction efficiency of total As for Fucus spiralis depended on the season and they speculate that the observed lower extraction efficiency in winter (February) could be due to either different distribution of arsenic species (i.e. not as water-soluble arsenic as in summer) or that the structure of the plant changes hindering extraction of water-soluble arsenic. It should be noted that the seasonal growth pattern of Fucales differs from that of Laminariales (including $S$. latissima and A. esculenta) in that fucalean metabolic activity is lowest during winter [33, 34]. This current work indicates the possibility of a different distribution of As in winter; i.e. when the kelp species were actively growing
[35], the As is predominantly accumulated as AsLs rather than water-soluble arsenic. This would thus be in agreement with Lai et al. [32] who further suggested that this distribution was related to thallus age, with higher proportions of water-soluble arsenic in older than in younger samples.

Acknowledgements Emeline Moreira is kindly thanked for her assistance with re-analysing a couple of samples for AsSugar measurement. Johannes Beere is thanked for the analysis on the Orbitrap for batch A. Urd Grandorf Bak is thanked for her helpful advice on seaweed.

Funding information This project has received funding from the European Union's Horizon 2020 research and innovation programme under the Marie Skłodowska-Curie grant agreement no. 656596.

\section{Compliance with ethical standards}

Conflict of interest The authors declare that they have no conflict of interest.

Open Access This article is distributed under the terms of the Creative Commons Attribution 4.0 International License (http:// creativecommons.org/licenses/by/4.0/), which permits unrestricted use, distribution, and reproduction in any medium, provided you give appropriate credit to the original author(s) and the source, provide a link to the Creative Commons license, and indicate if changes were made.

\section{References}

1. Ronan JM, Stengel DB, Raab A, Feldmann J, O'Hea L, Bralatei E, et al. High proportions of inorganic arsenic in Laminaria digitata but not in Ascophyllum nodosum samples from Ireland. Chemosphere. 2017;186:17-23. https://doi.org/10.1016/j.chemosphere.2017.07. 076 .

2. Francesconi KA. Arsenic species in seafood: origin and human health implications. Pure Appl Chem. 2010;82(2):373-81. https:// doi.org/10.1351/pac-con-09-07-01.

3. Authority EFS. Scientific opinion on arsenic in food. EFSA J. 2009;7(10):1351.

4. IARC International Agency for Research on Cancer: list of classifications, Volumes 1-120. http://monographs.iarc.fr/ENG/ Classification/latest_classif.php.

5. Petursdottir A, Sloth J, Feldmann J. Introduction of regulations for arsenic in feed and food with emphasis on inorganic arsenic, and implications for analytical chemistry. Anal Bioanal Chem. 2015:112. https://doi.org/10.1007/s00216-015-9019-1.

6. Muller SM, Ebert F, Raber G, Meyer S, Bornhorst J, Huwel S, et al. Effects of arsenolipids on in vitro blood-brain barrier model. Arch Toxicol. 2018;92(2):823-32. https://doi.org/10.1007/s00204-0172085-8.

7. Raab A, Newcombe C, Pitton D, Ebel R, Feldmann J. Comprehensive analysis of lipophilic arsenic species in a brown alga (Saccharina latissima). Anal Chem. 2013;85(5):2817-24. https:// doi.org/10.1021/ac303340t.

8. Taleshi MS, Jensen KB, Raber G, Edmonds JS, Gunnlaugsdottir H, Francesconi KA. Arsenic-containing hydrocarbons: natural compounds in oil from the fish capelin, Mallotus villosus. Chem Commun. 2008;39:4706-7. https://doi.org/10.1039/b808049f.

9. Garcia-Salgado S, Raber G, Raml R, Magnes C, Francesconi KA. Arsenosugar phospholipids and arsenic hydrocarbons in two species 
of brown macroalgae. EnvironChem. 2012;9(1):63-6. https://doi. org/10.1071/en 11164.

10. Yu XW, Xiong C, Jensen KB, Glabonjat RA, Stiboller M, Raber G, et al. Mono-acyl arsenosugar phospholipids in the edible brown alga Kombu (Saccharina japonica). Food Chem. 2018;240:81721. https://doi.org/10.1016/j.foodchem.2017.08.024

11. Viczek SA, Jensen KB, Francesconi KA. Arsenic-containing phosphatidylcholines: a new group of arsenolipids discovered in herring caviar. Angew Chem-Int Edit. 2016;55(17):5259-62. https://doi. org/10.1002/anie.201512031.

12. Amayo KO, Raab A, Krupp EM, Gunnlaugsdottir H, Feldmann J. Novel identification of arsenolipids using chemical derivatizations in conjunction with RP-HPLC-ICPMS/ESMS. Anal Chem. 2013;85(19):9321-7. https://doi.org/10.1021/ac4020935.

13. Meyer S, Matissek M, Mueller SM, Taleshi MS, Ebert F, Francesconi KA, et al. In vitro toxicological characterisation of three arsenic-containing hydrocarbons. Metallomics. 2014;6(5): 1023-33. https://doi.org/10.1039/c4mt00061g.

14. Meyer S, Schulz J, Jeibmann A, Taleshi MS, Ebert F, Francesconi $\mathrm{KA}$, et al. Arsenic-containing hydrocarbons are toxic in the in vivo model Drosophila meltanogaster. Metallomics. 2014;6(11):2010 4. https://doi.org/10.1039/c4mt00249k.

15. Niehoff AC, Schulz J, Soltwisch J, Meyer S, Kettling H, Sperling $\mathrm{M}$, et al. Imaging by elemental and molecular mass spectrometry reveals the uptake of an arsenolipid in the brain of Drosophila meltanogaster. Anal Chem. 2016;88(10):5258-63. https://doi.org/ 10.1021/acs.analchem.6b00333.

16. Meyer S, Raber G, Ebert F, Taleshi MS, Francesconi KA, Schwerdtle T. Arsenic-containing hydrocarbons and arseniccontaining fatty acids: transfer across and presystemic metabolism in the Caco-2 intestinal barrier model. Mol Nutr Food Res. 2015;59(10):2044-56. https://doi.org/10.1002/mnfr.201500286.

17. Stiboller M, Raber G, Lenters V, Gjengedal ELF, Eggesbø M, Francesconi KA. Arsenolipids detected in the milk of nursing mothers. Environ Sci Technol Lett. 2017;4(7):273-9. https://doi. org/10.1021/acs.estlett.7b00181.

18. Pétursdóttir ÁH, Fletcher K, Gunnlaugsdóttir H, Krupp E, Küpper FC, Feldmann J. Environmental effects on arsenosugars and arsenolipids in Ectocarpus (Phaeophyta). Environ Chem. 2016;13(1):21-33. https://doi.org/10.1071/EN14229.

19. Petursdottir AH, Rodrigues de Jesus J, Gunnlaugsdottir H, Feldmann J. Quantification of labile and stable non-polar arsenolipids in commercial fish meals and edible seaweed samples. J Anal At Spectrom. 2018;33(1):102-10. https://doi.org/10.1039/ c7ja00333a.

20. Glabonjat RA, Raber G, Jensen KB, Ehgartner J, Francesconi KA. Quantification of arsenolipids in the certified reference material NMIJ 7405-a (Hijiki) using HPLC/mass spectrometry after chemical derivatization. Anal Chem. 2014;86(20):10282-7. https://doi. org/10.1021/ac502488f.

21. Stévant P, Marfaing H, Duinker A, Fleurence J, Rustad T, Sandbakken I, et al. Biomass soaking treatments to reduce potentially undesirable compounds in the edible seaweeds sugar kelp (Saccharina latissima) and winged kelp (Alaria esculenta) and health risk estimation for human consumption. J Appl Phycol. 2018;30(3):2047-60. https://doi.org/10.1007/s10811-017-1343-8.

22. Bak UG, Mols-Mortensen A, Gregersen O. Production method and cost of commercial-scale offshore cultivation of kelp in the Faroe Islands using multiple partial harvesting. Algal Res. 2018;33:3647. https://doi.org/10.1016/j.algal.2018.05.001.
23. Stévant P, Rebours C, Chapman A. Seaweed aquaculture in Norway: recent industrial developments and future perspectives. Aquac Int. 2017;25(4):1373-90. https://doi.org/10.1007/s10499017-0120-7.

24. Gunnarsson K. Pari. Iceland: Reykjavik; 1997.

25. Petursdottir AH, Gunnlaudsdottir H, Jorundsdottir H, Raab A, Krupp EM, Feldmann J. Determination of inorganic arsenic in seafood: emphasizing the need for certified reference materials. Pure Appl Chem. 2012;84(2):191-202. https://doi.org/10.1351/pac-con11-10-03.

26. Amayo KO, Petursdottir A, Newcombe C, Gunnlaugsdottir H, Raab A, Krupp EM, et al. Identification and quantification of arsenolipids using reversed-phase HPLC coupled simultaneously to high-resolution ICPMS and high-resolution electrospray MS without species-specific standards. Anal Chem. 2011;83(9):3589 95. https://doi.org/10.1021/ac2005873.

27. Wolle MM, Conklin SD. Speciation analysis of arsenic in seafood and seaweed: part II-single laboratory validation of method. Anal Bioanal Chem. 2018;410(22):5689-702. https://doi.org/10.1007/ s00216-018-0910-4.

28. Craigie JS, Morris ER, Rees DA, Thom D. Alginate block structure in phaeophyceae from Nova Scotia: variation with species, environment and tissue-type. Carbohydr Polym. 1984;4(4):237-52. https:// doi.org/10.1016/0144-8617(84)90001-8.

29. Indergaard M, Skjåk-Bræk G, Jensen A (1990) Studies on the influence of nutrients on the composition and structure of alginate in Laminaria saccharina (L.) Lamour. (Laminariales, Phaeophyceae), vol 33. doi:https://doi.org/10.1515/botm.1990.33.3.277.

30. Indergaard M, Skjåk-Bræk G Characteristics of alginate from Laminaria digitata cultivated in a high-phosphate environment. In, Dordrecht, 1987. Twelfth International Seaweed Symposium. Springer Netherlands, pp 541-549.

31. Pétursdóttir ÁH, Gunnlaugsdóttir H. Selective and fast screening method for inorganic arsenic in seaweed using hydride generation inductively coupled plasma mass spectrometry (HG-ICPMS). Microchem J. 2019;144:45-50. https://doi.org/10.1016/j.microc. 2018.08.055.

32. Lai VWM, Cullen WR, Harrington CF, Reimer KJ. Seasonal changes in arsenic speciation in Fucus species. Appl Organomet Chem. 1998;12(4):243-51. https://doi.org/10.1002/(sici)10990739(199804)12:4<243::aid-aoc700>3.0.co;2-r.

33. Stengel D, Dring M. Morphology and in situ growth rates of plants of Ascophyllum nodosum (Phaeophyta) from different shore levels and responses of plants to vertical transplantation. Eur J Phycol. 1997;32(2):193-202. https://doi.org/10.1080/ 09670269710001737129 .

34. Lüning K. Growth strategies of three Laminaria species (Phaeophyceae) inhabiting different depth zones in the sublittoral region of Helgoland (North Sea). Mar Ecol Prog Ser. 1979;1:195207.

35. Sjotun K, Gunnarsson K. Seasonal growth pattern of an Icelandic Laminaria population (section Simplices, Laminariaceae, Phaeophyta) containing solid and hollow-stiped plants. Eur J Phycol. 1995;30(4):281-7. https://doi.org/10.1080/ 09670269500651061 .

Publisher's note Springer Nature remains neutral with regard to jurisdictional claims in published maps and institutional affiliations. 